\title{
Fasilitas Objek Wisata Dalam Pengembangan Desa Wisata : Kasus Bono di Kecamatan Taluk Meranti Kabupaten Pelalawan
}

\author{
SRI FEBDARINA
}

\author{
Sekolah Tinggi Pariwisata Riau \\ Jln. Patimura Pekanbaru Riau \\ E-mail : febdarinasri@gmail.com
}

\begin{abstract}
The purpose of the research to get detail contribution of hotel and restaurant in developing Bono Village Tourism at Teluk Meranti Bono Pelalawan. The specific purpose is to study the availablity of hotel and restaurant, training and also socializationthat received by hotel and restaurant's owner to develop Bono Village Tourism. In this study Hotel and Restaurant is viewed from social and culture's side in Hospitality which has twelve (12) elements, and this research are limited to study only for two elements, hotel and restaurant. The data was gathering from fifty (50) people from communities arround the village by having a discussion with them in one from. The data collected by a diret interview, discussion forum by using questionnaire and also direct observation. The research variable is type of hotels, tarining and socialization given to the communities to develop Bono Village Tourism. The data analysist by using SWOT analysist. The result of the study is training and socialisation is given to the hotel and restourant by government and Community Forum to improve the quality development of hotel and restaurant.
\end{abstract}

Keywords: Hotel and Restaurant

Partisipasi masyarakat sangat diperlukan dalam pengembangan suatu desa wisata. Hal ini dapat memberikan peluang usaha dan menghidupkan sektor-sektor lainnya sehingga perekonomian akan meningkat. Sektor tersebut antara lain adalah memberikan pelayanan yang baik pada wisatawan dalam penyediaan sarana penginapan, makanan dan minuman, penyediaan souvenir, kebersihan lingkungan serta keramah tamahan masyarakat sehingga wisatawan merasa nyaman dan puas yang nanti diharapkan mereka akan kembali lagi ke daerah tujuan wisata tersebut.

Objek wisata bono merupakan salah satu atraksi desa teluk meranti kabupaten pelalawan provinsi riau. Bono merupakan salah satu daya tarik objek wisata karena sensasi dan ketinggian gelombangnya sehingga banyak wisatawan minat khusus terutama surfer yang berasal dari manca negara maupun nasional. Hal ini tentu saja menjadi daya tarik tersendiri bagi teluk meranti sehingga dapat dikembangkan menjadi desa wisata. Untuk mewujudkan hal tersebut diatas diperlukan faktor pendukung agar para wisatawan dapat dengan mudah ke dan dari desa teluk meranti.

Daya tarik merupakan hal yang menarik wisatawan dan merupakan pusat dari industri pariwisata karena mampu menarik wisatawan mengunjunginya. Ataksi memiliki pola yang saling mendukung dan membutuhkan satu sama lainnya dan dapat juga digolongkan berdasarkan keutamaannya, yaitu atraksi primer dan sekunder.

Atraksi primer merupakan atraksi yang utama untuk dikunjungi wisatawan dalam suatu objek wisata sedangkan objek wisata sekunder merupakan atraksi pendukung yang umumnya terletak disekitar atraksi primer.

Dalam kegiatan kepariwisataan fasilitas juga diperlukan untuk melayani wisatawan ketika mengunjungi suatu atraksi. Dalam hal ini fasilitas berfungsi sebagai pendukung keberadaan aktaksi. Bila aktraksi dapat dikembangkan maka fasilitas juga mengikuti perkembangan demikian pula sekitarnya. Sementara itu kesertaan masyarakat dapat diwujudkan 
dengan adanya partisipasi masyarakat dengan memberikan layanan tambahan berupa penyediaan akomodasi, makan dan minum, hiburan serta layanan lainnya.

Keramah tamahan atau kesediaan masyarakat untuk menerima wisatawan merupakan hal yang mendasar. Dengan adanya kesediaan untuk menerima wisatawan maka wisatawan merasa diterima dan keamanannya terjamin. Hal ini bisa menimbulkan kesan buruk jika merasa menghadapi kendala selama berada di suatu destinasi. Untuk itu perlu adanya peningkatan kemampuan sumber daya manusia agar mampu memberikan pelayanan yang sesuai dengan harapan wisatawan.

Aksebilitas merupakan kemampuan untuk mencapai satu tujuan merupakan faktor yang penting. Beberapa daerah wisata tertentu sangat populer karena cukup dekat dan mudah dikunjungi dari daerah kota besar. Aksebilitas dapat diukur menururt waktu, biaya, frekuensi dan kesenangan. Semua aktaksi tergantung pada hubungan dengan tempat asal wisatawan. Kemampuan dicapai dengan mudah dan jumlah fasilitas dan pelayanan yang tersedia.

Atraksi dan fasilitas tidak dapat dicapai dengan mudah kalau belum ada infrastruktur dasar seperti sistem pengairan, jaringan komunikasi, fasilitas kesehatan terminal pengangkutan, sumber listrik dan energi, sistem pembuangan sampah, jalan, sistem keamanan dan transportasi.

Disamping itu industri kepariwisataan di desa teluk meranti perlu mendapatkan perhatian terutama yang berkaitan dengan kewirausahaan yang memberikan kontribusi pada pengembangan dan daya saing dengan berbagai cara antara lain dengan melakukan persaingan antara penduduk lokal dengan memberikan sesuai yang unik dengan standard pelayanan yang bersaing yang semakin melengkapi kebutuhan wisatawan.

Kebijaksanaan pemerintah juga menjadi faktor yang tak kalah pentingnya untuk suatu destinasi. Dukungan pemerintah dengan cara membangun infrastruktur, mendukung pembangunan fasilitas dan industri pariwisata serta melakukan promosi objek wisata bono. Artinya destinasi dan faktor pendukung saling terkait dan tak dapat dipisahkan.

Lebih lanjut ritchie (2009:70) mengatakan bahwa elemen insfrastruktur memiliki pengaruh yang besar terhadap destinasi "some elements of infratructure have a very direct influence on destination competitivenes". For examples. Transportation system. Water resources. Eectrical Generation transmission system. Sanitation and drainage. Education. Mail dan service. Telecomuication. Medical system. Financial system. Administrasion system. System national depends and public safety" Ritchie (2009:70)

Untuk menuju suatu destinasi dibutuhkan infrastruktur yang baik dan memadai agar wisatawan dapat dengan mudah mencapainya, disamping itu wisatawan yang datang memiliki kebutuhan dasar (basic needs) seperti air bersih, listrik, sanitasi dan drainasi, dan transportasi. Kenyataannya modal transportasi menuju desa teluk meranti terbatas pada mobil pribadi dan roda dua, jalan menuju ke sana masih banyak yang berlobang dan tergenang sehingga sangat melelahkan, dermaga ferry yang seadanya dan masih sangat tradisional. Sedangkan air bersih masih menggunakan air sungai. Listrik yang seharusnya menopang kegiatan wisatawan dan masyarakat belum begitu dapat dinikmati karena terbatasnya operasional PLN yang hanya dari pukul 06.00 wib sore s/d 07.00 wib pagi, sanitasi dan drainasi yang masih belum terkelola dengan baik sehingga menyebabkan sampah menumpuk yang menunjukkan kurangnya kebersihan di objek wisata bono. Demi tercipta sebuh destinasi wisata baru di desa teluk meranti kabupaten pelalawan provinsi riau dibutuhkan sebuha konsep seperti yang tergambar dalam bentuk problem tree seperti yang terlihat pada gambar berikut: 


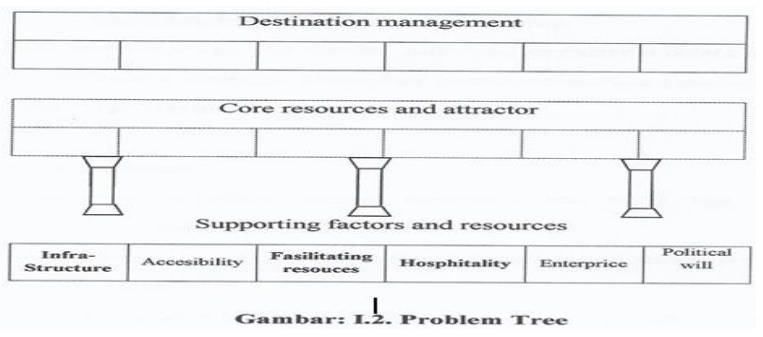

Berdasarkan uraian tersebut di atas maka perlu dilakukan penelitian tentang pertisipasi masyarakat desa wisata bono sebagai tujuan destinasi di kelurahan teluk meranti kecamatan teluk meranti kabupaten pelalawan provinsi riau.

Berdasarkan uraian tersebut di atas ditemuka permasalahan di desa teluk meranti sebagai berikut:
a) Masih kurangnya fasilitas hotel/homestay dan restoran
b) Masih minimnya perlengkapan hotel/homestay
c) Rumah makan dan warung hanya buka pada siang hari, sehingga wisatawan sulit menemukan rumah makan yang buka pada malam hari
d) Hotel belum dikelola secara profesional
e) Usaha hotel/homestay belum berkembang

Dari permasalahan diatas dituntut partisipasi masyarakat dalam menyediakan kebutuhan wisatawan sehingga diharapkan wisatawan merasa puas berkunjung ke desa wisata teluk meranti.

\section{METODE}

Penelitian ini menggunakan metode deskriptif. Demikian pula penelitian ini merupakan bagian penelitian lainnya yang dilakukan Yanti (2013), Novita (2013), Etika (2013) dan Wibowo (2013)

Penelitian ini dilakukan melalui beberapa trahap, yakni pertama, pengumpulan data mengenai hal-hal yang berhubungan dengan partisipasi masyarakat sekitar. Desa wisata bono di Kabupaten Pelalawan, Kecamatan Teluk Meranti. Kedua; menentukan instrumen penelitian, menentukan metode yang akan dipergunakan mencakup observasi, wawancara dan studi dokumentasi secara deskripdtif yakni melakukan pengamatan, merekam, mencatat dan mendokumentasikan keadaan objek wisata. Ketiga; menganalisis data yang sudah terkumpul kemudian disajikan dalam bentuk tesis.

\section{HASIL}

Teluk Meranti adalah salah satu Kecamatan yang ada di Kabupaten Pelalawan. Kecamatan ini terletak lebih kurang $125 \mathrm{Km}$ dari Pusat Ibukota Propinsi Riau dan lebih kurang $65 \mathrm{Km}$ dari pusat kota Kabupaten Pelalawan. Kecamatan Teluk Meranti dibentuk berdasarkan perda Nomor 06 Tahun 2005.

Adapun kecamatan Teluk Meranti berbatasan dengan: Sebelah Utara berbatasan dengan : sungai Apit Kab. Siak, Sebelah Selatan berbatasan dengan : Kab. INHU dan INHILS, ebelah Barat berbatasan dengan : Kecamatan Kerumutan dan Sebelah Timur berbatasan dengan Kecamatan Kuala Kampar.

Sebagai bekas sebuah kerajaan, kabupaten Pelalawan kaya akan aktifitas seni dan budaya yang masih dipertahankan dan digelar pada kegiatan-kegiatan tertentu baik itu pada pemberian gelar pembesaran maupun penobatan lainnya sesuai dengan yang telah diwariskan oleh sultan-sultan terdahulu. Berbagai aktifitas kesenian tumbuh dan tetap dilestarikan seperti:

a) Seni sastra, seperti : Nyanyian Panjang, Pantun, Bidal, Menumbai, dll.

b) Seni music, seperti: Gambus, Kompang, Gendang, Nafiiri, Ketobang, Gambang.

c) Seni tari, seperti: Zapin, Joget, Bagendong, Belian, Badewo, Silat Payung, dll.

d) Seni kerajinan masyarakat, seperti: anyaman Pandan, Daun Kopou, Bambu, Pertukangan Kayu, Sulaman dll.

Seni dan budaya yang dimiliki Teluk Meranti dapat menjadi daya tarik wisata pendukung bagi atraksi wisata gelomabang Bono, disamping objek wisata

p.ISSN: $2407-800 X \quad$ e.ISSN: 2541-4356 
lain yang terdapat disekitar Kecamatan Teluk Meranti seperti: Tasik Sarang Burung, Dari Desa Teluk Meranti Memudiki Anak sungai kita Sampai ke Tasik Sarang Burung. Tasik ini merupakan tempat migrasi burung-burung endemic dari belahan benua Australiaketika musim salju melanda benua tersebut. Hutan disekitar tasik ini ditumbuhi berbagai jenis kayu-kayuan antara lain:

(1) Ramin (Gonysstillus Bancanus kurz)

(2) Suntai (Palaqium Waisurifollum)

(3) Kempas (Kompassia Malaccaensis Maing)

(4) Meranti (Shoerea Sp)

(5) Bintangur (Colophyllum Sp), dan lain lain

Disini juga terdapat satwa-satwa yang dilindungi seperti :

(1) Beruang Madu (Helarctos Malayanus)

(2) Trenggeling (Manis Javanica)

(3) Kera Ekor Panjang (Macaca Fascicularis)

(4) Burung Enggang (Buceros Rhiniceros) Belibis (Dendrocybina Javanica)

Kawasan ini bertopografi datar dan merupakan ekosistem hutan dataran rendah dengan type ekosistem rawa gambut seluas $\pm 6.900 \mathrm{Ha}$.

Suaka Marga Satwa Kerumutan, Suaka Marga Satwa Kerumutan terletak di Des Kerumutan, lokasi ini dapat ditempuh dengan kendaraan darat dari pangkalan kerinci selama lebih kurang 2 jam perjalanan melalui jalan tanah berbatu. Dari peknabaru dapat ditempuh dari desa pangkalan kopan dengan waktu selama lebih kurang 4 jam. Luas Hutan \pm 93.222 Ha merupakan hutan perawan yang ditumbuhi aneka macam pepohonan dan hewan yang dilindungi diantaranya: Flora :Meranti (Shorea Sp), Punak (Tetrameriota Glabra Mig) Perupuk (Solena Permum Javanicum) Nipah (Nypa Fructicins) Rengas (Gluta Rengas) Pandan (Pandanus Sp), dll Fauna : Harimau Sumatera, Harimau Dahan Beruang Madu, Enggang, Monyet, Kuntul Putih, Ikan Arwana, Owa , Itik Liar

Berdasarkan informasi dari masyarakat (Kawi), sebenarnya daerah sekitar Teluk Meranti menyimpan beberapa potensi wisata yang cukup menarik untuk dikunjungi khususnya pada hutan lindung sungai Kerumutan yang memiliki selain potensi wisata flora dan fauna yang sudah dipaparkan di atas, hutan Kerumutan juga menyimpan cerita, legenda atau mitos, dari jembatan Geloga $\pm 2 \mathrm{Km}$ dengan mempergunakan speesboat, seperti:

1) Tempat memancing atau bahasa masyarakat tempatan memompeh, yaitu memancing secara tradisional dengan menggunakanbuluh panjang (bambu) dengan mata kail yang kecil dan tali pancing pendek. Jenis ikannya tertentu seperti Linca, Gook, Tampalo, jumlah ikannya banyak sekali, namun ikan-ikan tersebut tidak dapat dipancing atau dijaring. Dari sini perjalanan dilanjutkan menyelusuri aliran sungai dan bermalam diperkampungan. Lokasi objek ini \pm 20 menit dari jempatan lugu loga.

2) Golang-golang, golang adalah sejarah persukuan, suku Modang. Dahulu daerah suku Modang merupakan lokasi tempat jatuh golang bila dipanggil oleh suku Modang, dengan menyebut golanggolang maka air yang disungai tempat dimana golang tersebut akan jatuh akan menggelegak seperti air mendidih. Lokasi \pm 1 jam dari jembatan Lugu Loga.

3) Rasau Kelambu, adalah tempat dimana apabila kita menambatkan sampan atau speedboat dipulau Rasau, tidak seekor nyamuk pun akan berani menggigit pengunjung. Jarak tempuh \pm 1 jam 30 menit.

4) Pangkalan Bunian, merupakan perkampungan makhluk halus. Konon ceritanya dahulu terjalin interaksi yang baik antara manusia dan bunian, dimana manusia dahulunya apabila akan mengadakan perhelatan atau pesta dapat meminjam peralatan seperti

p.ISSN: $2407-800 X \quad$ e.ISSN: 2541-4356 
piring, mangkus, sendok atau padi kepada kaum bunian. Apabila meminjam padi maka manusia harus mengembalikan pinjaman tersebut. Setelah padi ditumbuk, kulit padi dikumpulkan dan kemudian diserahkan ke kaum Bunian tersebut. Hal itu berlangsung sampai tahun 1965, ketika ada peritiwa manusia yang meminjam padi tapi tidak dikembalikan. Akhirnya sekarang interaksi tersebut terputus.

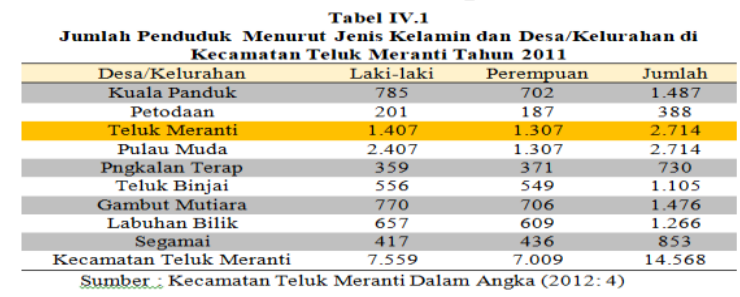

Dilihat dari data diatas, maka jumlah penduduk yang terbesar berada di Pulau Muda dan yang terkecil berada di Pangkalan Terap. Penduduk Desa Teluk Meranti sangat heterogen, terdiri dari beberapa suku dan hidup saling berdampingan.

\begin{tabular}{|c|c|c|c|c|c|}
\hline Desa/Kelurahan & Pertanian & $\begin{array}{l}\text { Perdagangan \& } \\
\text { Rumah Makan }\end{array}$ & Jasa & Lainnya & $\begin{array}{c}\text { Jumlah } \\
\text { Keluarga }\end{array}$ \\
\hline Kuala Panduk & 429 & 9 & 25 & 5 & 468 \\
\hline Petodaan & 118 & 9 & 0 & 0 & 127 \\
\hline Teluk Meranti & 342 & 47 & 29 & 174 & 592 \\
\hline Pulau Muda & 869 & 12 & 16 & 38 & 935 \\
\hline Pangkalan Terap & 178 & 9 & 0 & 0 & 187 \\
\hline Teluk Binjai & 237 & 15 & 18 & 8 & 278 \\
\hline Gambut Mutiara & 289 & 19 & 5 & 37 & 350 \\
\hline Labuhan Bilik & 319 & 20 & 11 & 42 & 392 \\
\hline Segamai & 212 & 26 & 0 & 0 & 238 \\
\hline $\begin{array}{c}\text { Kecamatan } \\
\text { Teluk Meranti }\end{array}$ & 2.993 & 166 & 104 & 304 & 3.567 \\
\hline
\end{tabular}

Dari sektor ekonomi pertanian merupakan sumber pendapatan penduduk yang terbesar, sector pertanian terbesar terdapatan tedapat Pulau Muda yaitu 869 dengan jumlah keluarga 935 keluarga, dengan kata lain sebagai besar keluarga di Pulau Muda adalah petani.

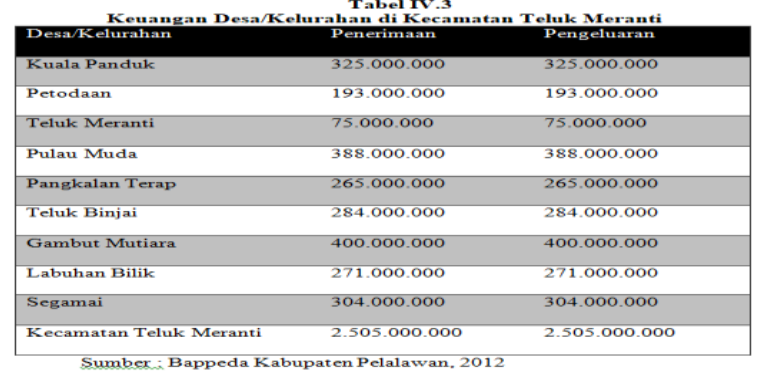

Jurnal Daya Saing (Vol. 4, No. 3 Oktober 2018)
Pendapatan Daerah di Desa Teluk Meranti 75.000.000, jadi dengan Desa Teluk Meranti di jadikan Desa Wisata, dana yang ada tidak mencukupi untuk pengembangan dan pembangunan infrasruktur, dan fasilitas pendukung lainnya.

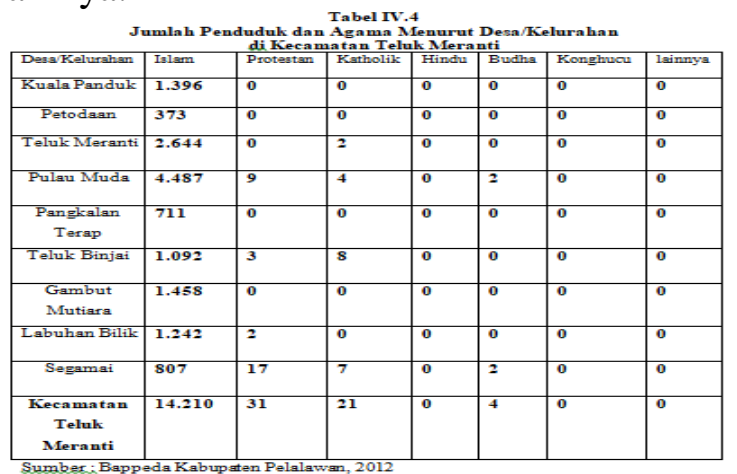

Kelurahan Teluk Meranti sebagai Ibukota Kecamatan memiliki fasilitas sosial yang cukup lengkap dibandingkan desa lainnya, seperti pasar, rumah makan, dermaga dan listrik. Energy listrik yang tersedia di kelurahan Teluk Meranti sebesar $100 \mathrm{KW}$, sehingga penerangan listrik hanya ada pada jam 18.00 - 07.00 pagi. Jaringan telekomunikasi (seluler), Pusat kesehatan masyarakat (Puskesmas), Polisi dan Militer serta sejumlah kantor perangkat kecamatan terdapat disini.

Disamping itu di Kelurahan Teluk Meranti terdapat dua rumah makan yang menyajikan masakan khas daerah (masakan kampung) dengan menu utama ikan sungai. Biasanya rumah makan ini melayani penumpang kapal yang melakukan perjalan dari Kerinci ke beberapa Kecamatan/desa yang ada disepanjang aliran Sungai Kampar hingga sampai ke Tanjung Batu kepulauan Riau. Disini juga terdapat penginapan (homestay) dengan tarif Rp.60.000,- sampai dengan Rp.80.000,- permalam, disamping rumah-rumah penduduk yang dapat disewa dengan tarif berkisar Rp 50.000,permalam. Jumlah penginapan yang ada di Teluk Meranti dua, dengan jumlah kamar \pm 15 kamar, serta fasilitas seadanya.

Eco-homestay merupakan salah satu konsep untuk mendukung pengembangan pariwisata pedesaan, hendaknya bernuansakan kedaerahan 
(tradisional), alami, bersih, sehat, aman, tertib dan ramah lingkungan. (hhtp://file.upi.edu)

\section{PEMBAHASAN}

Objek Wisata Bono terletak di Desa Teluk Meranti. Bono merupakan fenomena alam unik yang terjadi di Sungai Kampar Kabupaten Pelalawan Provinsi Riau. Bono adalah fenomena alam yang datang sebelum pasang. Air laut mengalir masuk dan bertemu dengan air sungai Kampar sehingga terjadi gelombang dengan kecepatan yang cukup tinggi, dan menghasilkansuara seperti suara Guntur dan suara angina kencang. Pada musim pasang tinggi, gelombang sungai Kampar bisa mencapai 4-6 meter, membentang dari tepi sungai ke tepi menutupi keseluruhan badan sungai. Peristiwa ini terjadi setiap hari, siang maupun malam hari terutama pada musim bulan penuh antara tanggal 10 sampai 20 bulan melayu (Arab), ketika pasang mati (bulan kecil) Bono bisa dikatakan tidak ada, kalaupun ada hanya berupa riak kecil ditempat yang sangat dangkal. Hal yang menarik turis ke objek wisata ini adalah kegiatan berenang, memancing, naik sampan dan lainnya (Syafruddin Mirohi, www.tribunpekanbaru.com/saf).

Tujuh peselancar dunia sudah bermain di gelombang Bono pada akhir November 2011 silam. Permainan peselancar dunia itu direkam menjadi promosi wisata nasional dan internasional asal Kabupaten Pelalawan. Departemen Pariwisata jugamenhadirkan 8 orang peselancar nasional. Dengan kedatangan mereka ini, sekaligus menepis mitos selama ini yang berkembang dimasyarakat bahwa gelombang Bono mengerikan. Tapi setelah mereka berhasil berselancar semua itu dapat ditepis, bahkan gelombang Bono ini juga merupakan sebuah aset/potensi wisata yang bertaraf internasional. Dan ternyata, mereka masih penasaran dan tertarik untuk datang kembali untuk berselancar dengan gelombang Bono di Teluk Meranti tersebut. Ini menandakan atau mengindikasikan bahwa gelombang Bono merupakan sebuah potensi wisata selancar di sungai yang berada di Provinsi Riau (Laporan Lismar Sumiati, Pangkalan Kerinci Redaksi@ riaupos.com).

Konon, Bono di Sungai Kampar adalah Bono jantan dan Bono betinanya berada di Sungai Rokan dekat Bagansiapiapi. Bono di Kuala Kampar ini berjumlah tuju ekor, bentuknya serupa kuda disebut induk Bono. Di musim pasang mati, Bono ini pergi ke Sungai Rokam menemui Bono betina, kemudian bersantai menuju ke Selat Malaka. Itulah sebabnya ketika bula kecil dan pasang mati, Bono tidak ditemukan di kedua sungai tersebut. Jika bulan mulai besar, kembalilah Bono ke tempat masingmasing, lalu main memudiki Sungan Kampar dan Sungai Rokan. Semakin penuh bulan di langit, semakin gembira Bono berpacumemudiki kedua sungai itu. Bagi penduduk daerah Kuala Kampar, Bono sudah mereka kenal sejak kecil. Sebab itulah tida aneh, apabila anak-anak, remaja dan orang dewasa menganggap Bono sebagai sahabatnya, tempat mereka bermain ketangkasan menunggangi Bono menggunakan perahu perahu (sampan) kecil.

Masyarakat Teluk Meranti adalah masyarakat laut dan memiliki kebiasaan dan kemampuan membaca karakter bulan, inilah yang menjadi perkiraan terjadinya Bono. Jadwal datangnya Bono dihitung berdasarkan kalender bulan/tahun melayu, yaitu (P) adalah bulan purnama/tengah bulan melayu ; $(\mathrm{M})$ adalah bulan mati/awal bulan melayu ; (B) adalah ombak/gelombang Bono suangai Kampar.

Biasanya tempat bermain Bono adalah temapt-tempat dimana Bono tidak terlalu besar atau dalam anak-anak Sungai Kampar yang memiliki Bono seperti Sungai Sangar, Turip, Serkap, Kutub dan Kerumutan. Permainan ini memang besar resikonya, sebab jika salah perhitungan perahu dapat dilemparkan Bono ke tebing sehingga hancur luluh. Tetapi dari pengamalaman sejak kecil, mereka, para pemain Bono ini sudah mengetahui betul dimana tempat yang aman bermain Bono. Dahulu, permainan Bono sering dilakuan

p.ISSN: $2407-800 X \quad$ e.ISSN: 2541-4356 
dengan upacara tertentu, tetapi kemudian menjadi permainan biasa dan dapat dilaksanakan sesuka hati. Tetapi hanya dilakukan pada siang hari, sedangkan malam hari betapapun beraninya mereka, belumlah ada yang mencobanya. Kalau taku atau ngeri untu bermain Bono, anda dapat menyaksikan Bono dari darat saja. Tetapi jika berani silahkan bermain Bono dengan perahuperahu kecil yang banyak disana. Yang penting anda harus pandai berenang, serta menunggangi Bono itu. Permainan ini mirip dengan selancar pada ombak-ombak di pantai, karena tempatnya luas dan tantangannya cukup besar.

Menurut legenda, Bono yang ada di Sungai Kampar seluruhnya berjumlah (tujuh) ekor, salah satu dari ketujuh bono itu yang merupakan anaknya ditembak olehmeriam Belanda sehingga yang terisa adalah 6 (enam) ekor. Karena anaknya mati dan menghilangkan ditembak Belanda, maka ke enam Bono tersebut mengamuk dan menghancurkan apa saja yang ada di dekat mereka. Secara bergantian dari yang besar hingga yang kecil Bono datang dalam masamasa tertentu untuk menunjukkan kekuatan dan kedahsyatannya bagaikan seorang induk yang marah dan mengamuk karena kehilangan anaknya.

Menurut cerita lain, kononnya, Bono yang ada di Sungai Kampar ini dalah Bono Jantan, sedangkan Bono Betinanya berada I Sungai Rokan. Di musim pasang mati, Bono Jantan menemui Bono Betina, kemudian mereka pergi bersama-sama ke selat Malaka untuk bermain dan bersantai disana. Apabila bulan mulai membesar mereka pun kembali ke tempat masing-masing, lalu bermain memudik sungai Kampar (yang Jantan) dan sungan Rokan (yang betinanya). Semakin penuh bulan di langit, semakin bertambah gembiranya mreka berpacu memudiki sungai itu, berderu, bergemuruh hingga sampai ke tempat masing-masing.

Akses jalan menuju wisata Bono tergolong mudah. Bisa melalui jalan darat dan bisa melalui jalan sungai. Jika melalui jalan darat hanya menempuh perjalan selama lebih kurang 4 jam. Dan dengan jalan sungai menggunakan speedboat lebih kurang 1 jam perlanan (Diposkan oleh Sabila, Rafita, Citra SM, Heny, Khoirun, Nisaq, Desi Agestia)

Untuk mencapai Lokasi Bono ini (Sungai Kampar Kecamatan Teluk Meranti Kabupaten Pelalawan) dapat ditempuh dengan menggunakan transportasi darat dari Pekanbaru ke Pangkalan Kerinci sekitar 70 $\mathrm{Km}$ dan dapat ditempuh dalam waktu 1,5 jam, Kemudian dilanjutkan perjalan darat menuju Teluk Meranti melalui Kecamatan Bunut lebih kurang perjalanan dapat ditempuh dengan waktu 4 jam. Selain itu perjalanan juga dapat dilakukan menggunakan sarana transportasi air, dari Pangkalan Kerinci (Pelabuhan di jembatan Pangkalan Kerinci) kita bisa.

Pengembangan desa wisata ditujukan untuk memberikan manfaat kepada pemenuhan kebutuhan masyarakat dan peningkatkan kualitas hidup dan kesejahteraan msayarakat. Tujuan ini sangat luhur dan positif, namun pada kenyataannya seringkali muncul berbagai permasalahan teknis meskipun seperti perencanaan yang dibuat telah dianggap sempurna. Permasalahan seperti acap kali muncul hamper disegala bidang pembangunan. Berikut ini kita akan mengamati upaya yang ditimbulkan oleh pembangunan hotel (homestay) dan restoran dalam bidang ekonomi, socialbudaya dan lingkungan.

Dampak ekonomi dalam kepariwisataan ada yang secara langsung maupun tidak langsung. Pengaruh secara langsung dari uang yang nyta digunakan oleh wisatawan di daerah tujuan wisata. Ketika wisatawan membayar hotel pada saat mereka menginap dan restoran pada saat mereka makan, akibatnya: Pendapatan daerah meningkat, Peluang kerja bagi masyarakat cukup banyak, Kemajuan bisnis kecil, bisnis kecil ini dapat berupa pelayanan taxi, toko cendramata, Harga tanah naik.

Pengaruh dibidang social Kepadatan wisatawan, seringkali jumlah wisatawan yang terkumpul atau berkunjung

$$
\text { p.ISSN: 2407-800X e.ISSN: 2541-4356 }
$$


menumpuk pada satu waktu, Pengaruh perilaku wisatawan, mendorong masyarakat local untuk bekerja dan mengejar sesuatu yang baru dan tampak baik yang dikenakan atau dilakukan wisatawan. Akibatnya tidak jarang wisatawan diperlakukan berdeda dari kebiasaan penduduk local untuk menarik wisatawan dan Migrasi, masyarakat pedesaan turut ambil bagian dengan bekerja di bidang jasa ditempat-tempat tujuan wisata, sehingga tidak sedikit diantara meraka yang meninggalkan kampung halamannya untuk pekerjaan ini.

Penurunan moral masyarakat., Kejahatan, terdapat hubungan antara pariwisata dengan kejahatan menusia yang membawa masyarakat banyak uang cenderung menggundang kejahatan. Pengaruh lain disekitarnya seperti perampokan.

Pengaruh terhadap kebudayaan kebudayaan manusia terdiri dari kepercayaan, nilai, sikap dan kelakuan, semua itu bagian dari masyarakat yang dilewati dari satu generasi ke generasi lain. Kebudayaan mempunyai cara pengungkapan yang berbeda seperti pekerjaan, pakaian, arsitektur, kerajinan, sejarah, budaya, bahasa, pendidikan, tradisi, kegiatan mengisi waktu luang, kesenian, music.

\section{SIMPULAN}

Hotel di desa teluk meranti terdiri dari 3 buah, dilihat dari sistem penetapan tarif kamar termasuk european plan yaitu harga kamar tidak termasuk makanan, ukuran dan jumlah kamar termasuk hotel kecil, berdasarkan jenis atau tipe tamu termasuk hotel wisatawan, berdasarkan lokasi hotel beach, lama tamu menginap antara 3-7 hari, hotel beroperasi sepanjang tahun, berdasarkan tarif hotel adalah tarif ekonomi, sedangkan restoran dilihat dari jenis dan variasi cukup baik $62 \%$, dilihat dari kualitas makanan, minuman dan pelayanan cukup baik $58 \%$, harga makanan dan minuman cukup baik $70 \%$, kebersihan sangat baik $74 \%$, physical attactiveness and comfort level of the establishments rumah makan cukup 56\%, lokasi cukup baik 56\%.
Pemerintah, LSM dan stakeholder telah berupaya melakukan pembinaan pada masyarakat sekitar dengan memberi penyuluhan dan pelatihan dan dikirim untuk magang ke luar daerah. Namun hasilnya belum sesuai dengan yang diharapkan.

\section{DAFTAR RUJUKAN}

Anonimous, Pelalawan Dalam Angka. BAPEDA, Kabupaten Pelalawan, 2012

Anonimous, Teluk Meranti Dalam Angka, BAPEDA, Kabupaten Pelalawan Dalam Angka, 2012.

Agus Sulastiyono.Drs.M.Si.1999. Manajemen Penyelenggaraan Hotel. Bandung. Alfabeta

Burkat and Medlik. Tourism Past, Present and Future. Penerbit. Heinemann. London. 1981.

Christie Mill, Robert. The Tourism Internasional busness Edisi Bahasa Indonesia. Penerbit. Grafindo. Jakarta. 2011.

Clare A.Gunn. Tourism Planning. Routledge. 2002.

Damanik, Jamanton \& Helmut.F. Weber. Perencanaan Ekowisata dari teori ke Aplikasi. Penerbit. Andi Yogyakarta.2006.

Fandy Tjipto \& Anastasia Diana. 2003. Total Quality Management. Edisi Revisi. Yogyakarta; ANDI.

Inskeep, Edward. Toursm Planning: an Integrated and Sustanable Development Approach. New York: John Wiley \& Sons, Inc, 1991.

Inskeep Edward, Tourism Planning, 1991

p.ISSN: 2407-800X

e.ISSN: $2541-4356$ 
Hariwijaya. Pedoman Penulisan ilmiah dan Tesis. Penerbit. Oryza. Yogyakarta. 2011.

Herdiansyah, Haris: Metodologi Penelitian Kualitaty u/ilmu-ilmu sosial. Penerbit. Salemba Humaida. Jakarta. 2010.

\section{Hariwijaya.H.Drs. dan Triton. PB.S.Si.M.Si.2011. Pedoman Penulisan Ilmiah Skripsi dan Tesis, Yogyakarta; Oryza.}

Hamzah Ahmad \& Ananda Santoso. Kamus Pintar Bahasa Indonesia. Surabaya; Fajar Mulya.

Harian Kompas edisi 29 Oktober 2009 mengatakan Depbudpar akan mengembangkan 200 desa wisata pada tahun 2010

Ike janita Dewi. Pemasaran pariwisata yang bertanggung jawab (Responsible Tourism Marketing). Kementrian Kebudayaan dan Pariwisata. Jakarta. 2011.

Damanik. Janiantan dan Frans Teguh. Manajemen Destinasi Pariwisata. Penerbit. Kepel Press. 2012.

Jero Wacik. SE.Ir. Pariwisata Pro Rakyat. 2010.

Jurnal pariwisata STPB. 2002.

J.R. Brent Ritchie, Geoffrey I. Crouch. The Competitive Destination. Cabi Publishing. 2002

John Swarbrooke. The Development and Management of Visitor Attractions. Second Edition. 2002.

Walker. John. T. Introduction to Hospitality. Six edition. Pearson. 2009.

Bowen. John. T - James. E. Marketing For Hospitality and Tourism. Peason. 2010.
Spillane. James. J. Ekonomi Pariwisata (Sejarah dan Prospeknya). Penerbit Kansius. Yogyakarta. 1985.

Kartajaya Hermawan. Konsep Pemasaran. Penerbit. Erlangga. Jakarta. 2009.

Kementrian Kebudayaan dan Pariwisata (2011:6)

Kottler \& Keller. Manajemen Pemasaran. Penerbit. Erlangga. Jakarta. 2009.

Ketetapan No. II/MPR/1993 mengenai Garis Besar Haluan Negara (GBHN) Bab IV

Keputusan Menteri Parpostel no Km 94/HK103/MPPT 1987

Loveloek. Christopher. Pemasaran jasa, manusia, teknologi, strategi perspektif Indonesia. Penerbit. Erlangga. Jakarta. 2011.

McIntosh. Tourism: Princiles, Practices, Philosopies. New York : John Wiley \& Sons. Inc. 1995.

Mill, Robert Cristie and Morrison. Alastair A. The Tourism System. New Jersey: Prenrice-Hal Inc.1985.

McInctosh, Robert (1995:10)

Mill, Robert Christie and Alastair M.

Morrison 1985. The Tourism System An Introductory Text Englewood Cliffs. New Jersey. Pretice Hall.

Moutindho. Wiz. Strategic Management in Tourism. CABI Publising. 2000.

Muljadi. A.J. Kepariwisataan dan Perjalanan. Grafindo. Jakarta. 2009.

Pendit. Nyoman. S. 1999. Ilmu Pariwisata Sebuah Pengantar Perdana. Jakarta: Pradya Pramita

p.ISSN: $2407-800 X \quad$ e.ISSN: 2541-4356 
Pitana. Pengantar Ilmu Pariwisata. Penerbit. Andi Yogyakarta. 2009.

Pitana. Sosiologi Pariwisata. Penerbit. Andi Yogyakarta. 2005.

Purnama Lingga. Strategic Marketing Plan. Penerbit. Gramedia. Jakarta. 2002.

Peraturan Pemerintah Republik Indonesia Nomor 50 Tahun 2011 tentang Rencana Induk Pembangunan kepariwisataan Nasional Tahun 2010 2025

Peraturan Menteri Kebudayaan dan Pariwisata Nomor PM.07/HK.001/MKP-2007; Kriteria untuk penetapan destinasi pariwisata unggulan.

Richie, Brent J.R dan I. Crouch Geoffrey: The Competitieve Destination A Sustainable Tourism Perspective. Cabi Pablishing 2003

Sumarwan, Gamai. 2004. Dasar-Dasar Pariwisata. Yogyakarta: ANDI

Suryadi, Drs dan IG. Silmenes Porang. 1980. Penuntun Penyusunan Paper Skripsi Thesis Desertasi Beserta Cara Pengetikannya. Surabaya; Usaha Nasional.

Usmara. A. Strategi Baru Manajemen Pemasaran. Penerbit. Amara Books. 2003.

Undang - Undang Pariwisata Indonesia No. 10 Tahun 2009, tentang Kepariwisataan

Undang - Undang No. 32 Tahun 2004, tentang Pemerintah Daerah

Undang - Undang No, 12 Tahun 2008, tentang Pemerintah Daerah

Undang - Undang Republik Indonesia No. 9, tentang Kepariwisataan
Undang - Undang Pariwisata Indonesia No. 10 Tahun 2009 tentang Kepariwisataan Menyebutkan bahwa destinasi pariwisata

Undang - Undang No. 32 Tahun 2004 tentang Pemerintahan daerah, yang telah diubah menjadi Undang-Undang 12 Tahun 2008 tentang Pemerintah Daerah

UU No. 9 Tahun 1990 tentang Kepariwisataan

UU No. 9 Tahun 1990. Tentang Kepariwisataan

Wardiyanta. M. Hum. Drs. 2006. Metode Penelitian Pariwisata. Yogyakarta; ANDI

Yoeti.

Oka,A.H.MBA.Drs.2008. Perencanaan Daerah Tujuan Wisata; Jakarta; Kompas.

.1989

$\begin{array}{llr}\text { Pariwisata } & \text { Nusantara } & \text { Indonesia. } \\ \text { Jakarta; } & \text { Direktorat } & \text { Jenderal } \\ \text { Pariwisata. } & & \end{array}$

Yoeti. Oka,A.H.MBA.Drs.1996. Pemasaran Pariwisata Terpadu. Bandung; Angkasa

Yoeti, Oka A. 1996. Pengantar Ilmu Pariwisata, Bandung; Angkasa

Yoeti, Oka A, dkk,2006. Pariwisata Budaya Masalah dan Solusinya. Jakarta; Pradnya Paramita 